\title{
The Intelligence of Octagonal Fuzzy Number to Determine the Fuzzy Critical Path: A New Ranking Method
}

\author{
S. Narayanamoorthy and S. Maheswari \\ Department of Mathematics, Bharathiar University, Coimbatore 641 046, India \\ Correspondence should be addressed to S. Narayanamoorthy; snm_phd@yahoo.co.in
}

Received 8 December 2015; Accepted 23 February 2016

Academic Editor: Piotr Luszczek

Copyright ( $) 2016$ S. Narayanamoorthy and S. Maheswari. This is an open access article distributed under the Creative Commons Attribution License, which permits unrestricted use, distribution, and reproduction in any medium, provided the original work is properly cited.

\begin{abstract}
This research paper proposes a modified ranking approach to determine the critical path in fuzzy project network, where the duration of each activity time is represented by an octagonal fuzzy number. In this method, a modified subtraction formula is carried out on fuzzy numbers. This modified method works well on fuzzy backward pass calculations as there will be no negative time. The analysis is expected to show that the fuzzy number which is used in this paper is more effective in determining the critical path in a fuzzy project network and possibility of meeting the project time. A numerical example is given and compared with trapezoidal, triangular fuzzy numbers through proposed ranking method.
\end{abstract}

\section{Introduction}

The range of project management application has significantly expanded. The project management concerning the scheduling and monitoring progress within the cost, time, and duration is becoming important to obtain competitive priorities such as time delivery. The activity duration time in project is known and deterministic; critical path method (CPM) has been demonstrated to be a useful tool in the planning and control of complicated projects in management and engineering applications. The critical path method worked out at the beginning of the 1960s. In reality, it is often difficult to obtain estimates of activity time, due to the uncertainty of information. In this situation, Zadeh proposed an alternative way of this kind of decision-making environment.

\section{Related Work}

Critical path method (CPM) has been demonstrated to be a useful tool in managing projects in an efficient manner to meet the challenges presented by Hillier and Lieberman [1]. In business management, Ahuja et al. [2] discussed factory production using critical path method. Mon et al. [3] and
Dubois et al. [4] presented a project network defined as a set of activities that must be performed according to precedence constraints stating which must start after the completion of other specified activities. Natarajan et al. [5] and Sivarenthinamohan [6] presented the backward pass which is performed to calculate the fuzzy latest-start and latest finish times. Khalaf [7] applied fuzzy theory to find fuzzy total float, free float, and fuzzy independent float for a project network with activity duration modeled as triangular fuzzy numbers. Oladeinde and Itsisor [8] obtained the fuzzy early start, early finish, fuzzy latest start, and latest finish as well as the critical activities with triangular activity duration. Shahsavari Poura et al. [9] presented another fuzzy critical path method where the processing times of all activities follow trapezoidal fuzzy numbers. Soundararajan et al. [10] ascertained that Artificial Neural Network is an alternative method for predicting the mechanical properties and appropriate results can be estimated rather than measured, thereby reducing the testing time and cost.

Zadeh [11] introduced an alternative way to deal with imprecise data to employ the concept of fuzziness. Liang and Han [12] developed an algorithm which is presented to perform critical path analysis in a fuzzy environment. Jain 
[13] proposed the concept of fuzzy numbers. Chanas and Radosinski [14] analyzed the use of fuzzy numbers in the network planning. M. H. Oladeinde and C. A. Oladeinde [15] considered the effectiveness of the decision-makers' risk attitude index for fuzzy critical path analysis. Han et al. [16] presented the fuzzy critical path method to find out airport's ground critical operation processes. Lin [17] presented practical support to the management of organizations in order to make a formation program of human resources. Ravi Shankar et al. [18] used trapezoidal fuzzy numbers to rank the set of fuzzy numbers in a fuzzy project network. Karimirad et al. [19] anticipated a novel method for ranking of fuzzy numbers is proposed that is based on the real numbers. Rotarescu [20] offered practical support to the management of organizations in order to make a formation program of human resources. Kazemi et al. [21] used the fuzzy Delphi-analytical hierarchy process method and also the ranking method would help product designers to decide on appropriate materials in a consistent method.

This paper presents another approach, which has not been proposed in the literature so far, to analyze the critical path in a project network with fuzzy activity times. A modified arithmetic operation is used on octagonal, trapezoidal, and triangular fuzzy numbers and applied to the float time for each activity in the fuzzy project network. We compared trapezoidal and triangular with octagonal fuzzy numbers and which one is more effective to determining the activity criticalities to find the critical path in a network.

\section{Preliminaries}

In this section, we present the most basic notations and definitions, which we used throughout this work. We start with defining a fuzzy set.

3.1. Fuzzy Set. Let $X$ be a set. A fuzzy set $A$ on $X$ is defined to be a function $A: X \rightarrow[0,1]$ or $\mu_{A}: X \rightarrow[0,1]$. Equivalently, A fuzzy set $A$ is defined to be the class of objects having the following representation: $A=\left\{\left(x, \mu_{A}(x), x \in X\right)\right\}$ where $\mu_{A}$ : $X \rightarrow[0,1]$ is a function called the membership function of $A$.

3.2. Fuzzy Number. The fuzzy number $A$ is a fuzzy set whose membership function satisfies the following conditions:

(1) $\mu_{A}(x)$ is piecewise continuous.

(2) A fuzzy set $A$ of the universe of discourse $X$ is convex.

(3) A fuzzy set of the universe of discourse $X$ is called a normal fuzzy set if $x_{i} \in X$ exists.

3.3. Trapezoidal Fuzzy Number. A fuzzy number with membership function in the form

$$
\mu_{A}(x)= \begin{cases}\frac{x-a}{b-a}, & a \leq x \leq b \\ 1, & b \leq x \leq c \\ \frac{d-x}{d-c}, & c \leq x \leq d \\ 0, & \text { otherwise }\end{cases}
$$

is called a trapezoidal fuzzy number $A=(a, b, c, d)$.
3.4. Triangular Fuzzy Number. A fuzzy number with membership function in the form

$$
\mu_{A}(x)= \begin{cases}\frac{x-a}{b-a}, & a \leq x \leq b \\ \frac{x-c}{b-c}, & b \leq x \leq c \\ 0, & \text { otherwise }\end{cases}
$$

is called a triangular fuzzy number $A=(a, b, c)$.

\section{Formulation of Octagonal Fuzzy Number for Ranking}

In the current section, we present a new method for ranking fuzzy numbers. Ravi Shankar et al. and Narayanamoorthy and Maheswari $[18,22]$ have studied ranking methods using triangular and trapezoidal fuzzy numbers. Here we have extended ranking methods and modified arithmetic operations using octagonal fuzzy number to find fuzzy critical path. Octagonal fuzzy number and modified arithmetic operations are presented in the following subsections.

4.1. Octagonal Fuzzy Number. Here, we present a method for ranking fuzzy numbers. This method calculates the ranking scores of the octagonal fuzzy number. Fuzzy numbers $(A, B, C)$ are an octagonal fuzzy number denoted by $(A, B, C)=(a, b, c, d, e, f, g, h)$ where $(a, b, c, d, e, f, g, h)$ are real numbers and its membership functions $\mu_{A}(x), \mu_{B}(x)$, and $\mu_{C}(x)$ are given below:

$$
\begin{gathered}
\mu_{A}(x)= \begin{cases}\frac{x-a}{d-a}, & a \leq x \leq d \\
1, & d \leq x \leq e \\
\frac{x-h}{e-h}, & e \leq x \leq h \\
0, & \text { otherwise }\end{cases} \\
\mu_{B}(x)= \begin{cases}\frac{x-a}{c-a}, & a \leq x \leq c \\
0.8, & c \leq x \leq f \\
\frac{x-h}{f-h}, & f \leq x \leq h \\
0, & \text { otherwise, }\end{cases} \\
\mu_{C}(x)= \begin{cases}\frac{x-a}{b-a}, & a \leq x \leq b \\
0.6, & b \leq x \leq g \\
\frac{x-g}{g-h}, & g \leq x \leq h \\
0, & \text { otherwise. }\end{cases}
\end{gathered}
$$

Figure 1 depicts that the graphical representation of an octagonal fuzzy number $(A, B, C)=(a, b, c, d, e, f, g, h)$.

4.2. Modified Arithmetic Operations. Let $A_{1}$ and $A_{2}$ be two octagonal fuzzy numbers parameterized by $\left(a_{1}, a_{2}, a_{3}\right.$, $\left.a_{4}, a_{5}, a_{6}, a_{7}, a_{8}\right)$ and $\left(b_{1}, b_{2}, b_{3}, b_{4}, b_{5}, b_{6}, b_{7}, b_{8}\right)$, respectively. 


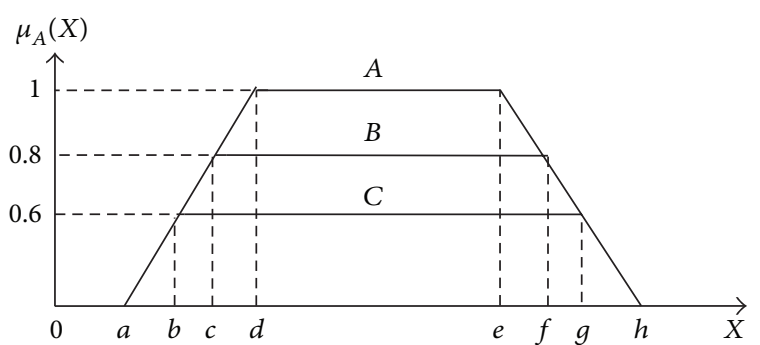

FIGURE 1: Graphical representation of an octagonal fuzzy number.

The simplified fuzzy number arithmetic operations between the fuzzy numbers $A_{1}$ and $A_{2}$ are as follows:

Fuzzy numbers addition: $\oplus:\left(a_{1}, a_{2}, a_{3}, a_{4}, a_{5}, a_{6}, a_{7}\right.$, $\left.a_{8}\right) \oplus\left(b_{1}, b_{2}, b_{3}, b_{4}, b_{5}, b_{6}, b_{7}, b_{8}\right)=\left(a_{1}+b_{1}, a_{2}+b_{2}, a_{3}+\right.$ $\left.b_{3}, a_{4}+b_{4}, a_{5}+b_{5}, a_{6}+b_{6}, a_{7}+b_{7}, a_{8}+b_{8}\right)$.

Fuzzy numbers subtraction: $\ominus:\left(a_{1}, a_{2}, a_{3}, a_{4}, a_{5}, a_{6}\right.$, $\left.a_{7}, a_{8}\right) \ominus\left(b_{1}, b_{2}, b_{3}, b_{4}, b_{5}, b_{6}, b_{7}, b_{8}\right)=\left(\max \left(0, a_{1}-b_{8}\right)\right.$, $\max \left(0, a_{2}-b_{7}\right), \max \left(0, a_{3}-b_{6}\right), \max \left(0, a_{4}-b_{5}\right)$, $\max \left(0, a_{5}-b_{4}\right), \max \left(0, a_{6}-b_{3}\right), \max \left(0, a_{7}-b_{2}\right)$, $\left.\max \left(0, a_{8}-b_{1}\right)\right)$.

\section{Fuzzy Critical Path Algorithm Based on Ranking of Octagonal Fuzzy Number-Proposed Method}

One of the main aims of this paper is to extend the fuzzy critical path algorithm for octagonal fuzzy number. Consider the fuzzy project network, where the duration time of each activity in a fuzzy project network is represented by fuzzy numbers.

\subsection{Algorithm}

Step 1. Calculate $\widetilde{E_{i}^{s}}$ s and $\widetilde{E_{i}^{f}}$, s using $\widetilde{E_{i}^{s}}=\max _{j \in p(i)}\left\{\widetilde{E_{j}^{s}} \oplus \widetilde{t_{j}}\right\}$ and $\widetilde{E_{i}^{f}}=\widetilde{E_{i}^{s}} \oplus \widetilde{t_{j}}$.

Step 2. Calculate $\widetilde{L_{i}^{f}}$, s and $\widetilde{L_{i}^{s}}$, s using $\left.\widetilde{L_{i}^{f}}=\min _{j \in p(i)} \widetilde{L_{j}^{f}} \ominus \widetilde{t_{j}}\right\}$ and $\widetilde{L_{i}^{s}}=\widetilde{L_{i}^{f}} \ominus \widetilde{t_{j}}$.

Step 3. Calculate $\widetilde{T_{i}^{F}}$ for each activity $(i, j)$ using $\widetilde{T_{i}^{F}}=\widetilde{L_{i}^{s}} \ominus \widetilde{E_{i}^{s}}$ and $\widetilde{T_{i}^{F}}=\widetilde{L_{i}^{f}} \ominus \widetilde{E_{i}^{f}}$.

Step 4. Find all the possible paths and calculate the total slack fuzzy time of each path.

Step 5. Rank the total slack fuzzy time of each path using Sanguansat and Chen ranking method.

5.2. Procedure for Proposed Ranking Method. Here we present a new ranking method for fuzzy critical path.

Assume that there are $n$ fuzzy numbers $A=\left\{A_{1}, A_{2}\right.$, $\left.A_{3}, \ldots, A_{n}\right\}$.
Step 1. Transform each octagonal fuzzy number into a standardized fuzzy number $A_{i}^{*}$ :

$$
\begin{aligned}
A_{i}^{*} & =\left(\frac{a_{i 1}}{k}, \frac{a_{i 2}}{k}, \frac{a_{i 3}}{k}, \frac{a_{i 4}}{k}, \frac{a_{i 5}}{k}, \frac{a_{i 6}}{k}, \frac{a_{i 7}}{k}, \frac{a_{i 8}}{k}\right) \\
& =\left(a_{i 1}^{*}, a_{i 2}^{*}, a_{i 3}^{*}, a_{i 4}^{*}, a_{i 5}^{*}, a_{i 6}^{*}, a_{i 7}^{*}, a_{i 8}^{*}\right),
\end{aligned}
$$

where $k=\max \left\|a_{i j}\right\|,\left|a_{i j}\right|$ denotes the absolute value of $a_{i j}$, and $\left\|a_{i j}\right\|$ denotes the upper bound of $\left|a_{i j}\right|, 1 \leq i \leq n$ and $1 \leq j \leq 8$.

Step 2. Calculate standard deviation of each standardized fuzzy number $A_{i}^{*}$ :

$$
\sigma_{A_{i}^{*}}=\sqrt{\frac{\sum_{j=1}^{8}\left(a_{i j}^{*}-\overline{a_{i}}\right)^{2}}{8-1}},
$$

where $\overline{a_{i}}$ denotes the mean of the values $a_{i 1}^{*}, a_{i 2}^{*}, a_{i 3}^{*}, a_{i 4}^{*}, a_{i 5}^{*}$, $a_{i 6}^{*}, a_{i 7}^{*}$,and $a_{i 8}^{*}$ and $1 \leq i \leq n$.

Step 3. Calculate the areas $\mathrm{Area}_{i L}^{-}$and $\mathrm{Area}_{i R}^{-}$of each standard fuzzy number $A_{i}^{*}$ where

$$
\begin{aligned}
& \operatorname{Area}_{i L}^{-}=\frac{\left(a_{i 1}^{*}+1\right)+\left(a_{i 2}^{*}+1\right)+\left(a_{i 3}^{*}+1\right)+\left(a_{i 4}^{*}+1\right)}{4}, \\
& \operatorname{Area}_{i R}^{-}=\frac{\left(a_{i 5}^{*}+1\right)+\left(a_{i 6}^{*}+1\right)+\left(a_{i 7}^{*}+1\right)+\left(a_{i 8}^{*}+1\right)}{4} .
\end{aligned}
$$

Then, calculate the areas $\mathrm{Area}_{i L}^{+}$and $\mathrm{Area}_{i R}^{+}$of each standardized fuzzy number $A_{i}^{*}$ where

$$
\begin{aligned}
& \operatorname{Area}_{i L}^{+}=\frac{\left(1-a_{i 1}^{*}\right)+\left(1-a_{i 2}^{*}\right)+\left(1-a_{i 3}^{*}\right)+\left(1-a_{i 4}^{*}\right)}{4}, \\
& \operatorname{Area}_{i R}^{+}=\frac{\left(1-a_{i 5}^{*}\right)+\left(1-a_{i 6}^{*}\right)+\left(1-a_{i 7}^{*}\right)+\left(1-a_{i 8}^{*}\right)}{4} .
\end{aligned}
$$

Step 4. Calculate the values $X I_{A_{i}^{*}}$ and $X D_{A_{i}^{*}}$ of each standardized fuzzy number $A_{i}^{*}$,

$$
\begin{aligned}
X I_{A_{i}^{*}} & =\text { Area }_{i L}^{-}+\text {Area }_{i R}^{-}, \\
X D_{A_{i}^{*}} & =\text { Area }_{i L}^{+}+\text {Area }_{i R}^{+}+\sigma_{A_{i}^{*}} .
\end{aligned}
$$

Step 5. Calculate the ranking score $A_{i}^{*}$ of each standardized fuzzy number $A_{i}^{*}$ :

$$
\operatorname{Score}\left(A_{i}^{*}\right)=\frac{X I_{A_{i}^{*}}-X D_{A_{i}^{*}}}{X I_{A_{i}^{*}}+X D_{A_{i}^{*}}+k},
$$

where

$$
k=\left\{\begin{array}{lll}
1 & X I_{A_{i}^{*}}-X D_{A_{i}^{*}} \geq 0, & \\
-1 & \text { otherwise } & 1 \leq i \leq n .
\end{array}\right.
$$


TABLE 1: Total float of each activity in the fuzzy project network.

\begin{tabular}{lcccc}
\hline Activity & Trapezoidal fuzzy activity time & Total float & Triangular fuzzy activity time & Total float \\
\hline $1-2$ & $(2,5,5,7)$ & $(0,0,7,25)$ & $(2,5,7)$ & $(4,6,9)$ \\
$1-3$ & $(4,6,7,9)$ & $(0,0,3,21)$ & $(3,5,8)$ & $(0,0,25)$ \\
$1-5$ & $(3,5,6,8)$ & $(0,10,15,30)$ & $(0,10,30)$ \\
$2-5$ & $(6,8,9,12)$ & $(0,0,7,25)$ & $(5,7,10)$ & $(0,0,25)$ \\
$2-4$ & $(5,7,8,10)$ & $(0,4,8,28)$ & $(6,9,13)$ & $(0,4,28)$ \\
$3-6$ & $(6,9,10,13)$ & $(0,0,4,22)$ & $(8,11,16)$ & $(0,0,22)$ \\
$3-5$ & $(8,11,12,16)$ & $(0,0,3,21)$ & $(10,15,20)$ & $(0,0,21)$ \\
$4-7$ & $(10,15,15,20)$ & $(0,4,8,28)$ & $(12,15,20)$ & $(0,4,28)$ \\
$5-7$ & $(12,15,16,20)$ & $(0,0,3,21)$ & $(13,16,20)$ & $(0,0,22)$ \\
$6-7$ & $(13,16,17,20)$ & $(0,0,4,22)$ &
\end{tabular}

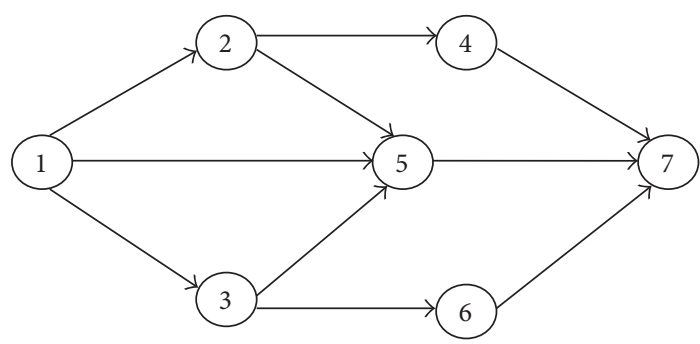

FIGURE 2: The network structure of project.

TABLE 2: Total fuzzy slack time for each path in fuzzy project network.

\begin{tabular}{lcc}
\hline Path & $\begin{array}{c}\text { Total fuzzy slack } \\
\text { time }(a, b, c)\end{array}$ & $\begin{array}{c}\text { Total fuzzy slack } \\
\text { time }(a+c, b, b+c)\end{array}$ \\
\hline $1-2-4-7$ & $(0,8,81)$ & $(81,0,89)$ \\
$1-2-5-7$ & $(0,0,71)$ & $(71,0,71)$ \\
$1-5-7$ & $(0,10,51)$ & $(51,10,28)$ \\
$1-3-5-7$ & $(0,0,63)$ & $(63,0,63)$ \\
$1-3-6-7$ & $(0,0,65)$ & $(65,0,65)$ \\
\hline
\end{tabular}

\section{Numerical Example}

To illustrate the proposed method, consider Figure 2, where node 1 is preliminary design, Node 2 is evaluation of design, Node 3 is contract negotiation, Node 4 is preparation of fabrication plant, Node 5 is final design, Node 6 is fabrication of product, and Node 7 is shipment of product to owner.

From Figure 2, the activity, trapezoidal fuzzy activity time, triangular fuzzy activity time, and total float values are stated in Table 1.

The possible paths, total float, and total fuzzy slack times are calculated and listed in Table 2.

6.1. Sanguansat and Chen Ranking Method for Triangular Fuzzy Number. The calculations are carried out using triangular fuzzy numbers ranking formula by Narayanamoorthy and Maheswari [22]:

$$
\begin{aligned}
A_{1}^{*} & =(0.910,0,1), \\
\overline{a_{1}} & =0.636,
\end{aligned}
$$

$$
\begin{aligned}
A_{2}^{*} & =(0.797,0,0.797), \\
\overline{a_{2}} & =0.531, \\
A_{3}^{*} & =(0.573,0.112,0.685), \\
\overline{a_{3}} & =0.456, \\
A_{4}^{*} & =(0.707,0,0.707), \\
\overline{a_{4}} & =0.471, \\
A_{5}^{*} & =(0.730,0,0.730), \\
\overline{a_{5}} & =0.486, \\
\sigma_{A_{1}^{*}} & =0.552, \\
\sigma_{A_{2}^{*}} & =0.458, \\
\sigma_{A_{3}^{*}} & =0.301, \\
\sigma_{A_{4}^{*}} & =0.406, \\
\sigma_{A_{5}^{*}} & =0.420,
\end{aligned}
$$

Area $_{1 L}^{-}=1.455$,

Area $_{2 L}^{-}=1.398$,

Area $_{3 L}^{-}=1.342$,

Area $_{4 L}^{-}=1.353$,

Area $_{5 L}^{-}=1.365$,

Area $_{1 R}^{-}=1.5$,

Area $_{2 R}^{-}=1.398$,

Area $_{3 R}^{-}=1.398$,

Area $_{4 R}^{-}=1.353$,

Area $_{5 R}^{-}=1.365$,

Area $_{1 L}^{+}=0.545$, 
TABLE 3: Chen rank of total fuzzy slack time for each path.

\begin{tabular}{lccc}
\hline Path & $X I_{A_{i}^{*}}$ & $X D_{A_{i}^{*}}$ & $\operatorname{Score}\left(A_{i}^{*}\right)$ \\
\hline $1-2-4-7$ & 2.955 & 1.597 & 0.244 \\
$1-2-5-7$ & 2.796 & 1.66 & 0.208 \\
$1-5-7$ & 2.74 & 1.559 & 0.222 \\
$1-3-5-7$ & 2.706 & 1.698 & 0.186 \\
$1-3-6-7$ & 2.73 & 1.69 & 0.191 \\
\hline
\end{tabular}

TABLE 4: Total fuzzy slack time for each path in fuzzy project network.

\begin{tabular}{lcc}
\hline Path & $\begin{array}{c}\text { Total fuzzy slack } \\
\text { time }(a, b, c, d)\end{array}$ & $\begin{array}{c}\text { Total fuzzy slack time } \\
(a+d, b, c, b+c)\end{array}$ \\
\hline $1-2-4-7$ & $(0,8,23,81)$ & $(81,8,23,31)$ \\
$1-2-5-7$ & $(0,0,17,71)$ & $(71,0,17,17)$ \\
$1-5-7$ & $(0,10,18,51)$ & $(51,10,18,28)$ \\
$1-3-5-7$ & $(0,0,9,63)$ & $(63,0,9,9)$ \\
$1-3-6-7$ & $(0,0,11,65)$ & $(65,0,11,11)$ \\
\hline
\end{tabular}

$$
\begin{aligned}
& \text { Area }_{2 L}^{+}=0.601, \\
& \text { Area }_{3 L}^{+}=0.657, \\
& \text { Area }_{4 L}^{+}=0.646, \\
& \text { Area }_{5 L}^{+}=0.635, \\
& \text { Area }_{1 R}^{+}=0.5, \\
& \text { Area }_{2 R}^{+}=0.601, \\
& \text { Area }_{3 R}^{+}=0.601, \\
& \text { Area }_{4 R}^{+}=0.646, \\
& \text { Area }_{5 R}^{+}=0.635 .
\end{aligned}
$$

By using Area $_{i L}^{-}$, Area ${ }_{i R}^{-}$, Area $_{i L}^{+}$, Area $_{i R}^{+}$, and $\sigma_{A_{i}^{*}}$ from this, we can get the values of $X I_{A_{i}^{*}}, X D_{A_{i}^{*}}$, and $\operatorname{Score}\left(A_{i}^{*}\right)$ values. The values are calculated and tabulated in Table 3.

Here the path having minimum rank score is 1-3-5-7. So the critical path for the fuzzy project network is 1-3-5-7.

\subsection{Sanguansat and Chen Ranking Method for Trapezoidal} Fuzzy Number. The paths and total fuzzy slack times are given in Table 4.

The calculations are carried out using trapezoidal fuzzy numbers ranking formula by Ravi Shankar et al. [18]:

$$
\begin{aligned}
A_{1}^{*} & =(1,0.098,0.283,0.382), \\
\overline{a_{1}} & =0.440, \\
A_{2}^{*} & =(0.876,0,0.209,0.209), \\
\overline{a_{2}} & =0.323,
\end{aligned}
$$

$$
\begin{aligned}
A_{3}^{*} & =(0.629,0.123,0.222,0.345), \\
\overline{a_{3}} & =0.329, \\
A_{4}^{*} & =(0.777,0,0.111,0.111), \\
\overline{a_{4}} & =0.249, \\
A_{5}^{*} & =(0.802,0,0.135,0.135), \\
\overline{a_{5}} & =0.268, \\
\sigma_{A_{1}^{*}} & =0.389, \\
\sigma_{A_{2}^{*}} & =0.379, \\
\sigma_{A_{3}^{*}} & =0.216, \\
\sigma_{A_{4}^{*}} & =0.354, \\
\sigma_{A_{5}^{*}} & =0.360,
\end{aligned}
$$$$
\text { Area }_{1 L}^{-}=1.549 \text {, }
$$$$
\text { Area }_{2 L}^{-}=1.438 \text {, }
$$$$
\text { Area }_{3 L}^{-}=1.376 \text {, }
$$$$
\text { Area }_{4 L}^{-}=1.388 \text {, }
$$$$
\text { Area }_{5 L}^{-}=1.401 \text {, }
$$$$
\text { Area }_{1 R}^{-}=1.332 \text {, }
$$$$
\text { Area }_{2 R}^{-}=1.209 \text {, }
$$$$
\text { Area }_{3 R}^{-}=1.283 \text {, }
$$$$
\text { Area }_{4 R}^{-}=1.111 \text {, }
$$$$
\text { Area }_{5 R}^{-}=1.135 \text {, }
$$$$
\text { Area }_{1 L}^{+}=0.549 \text {, }
$$$$
\text { Area }_{2 L}^{+}=0.562 \text {, }
$$$$
\text { Area }_{3 L}^{+}=0.624 \text {, }
$$$$
\text { Area }_{4 L}^{+}=0.611 \text {, }
$$$$
\text { Area }_{5 L}^{+}=0.599 \text {, }
$$$$
\text { Area }_{1 R}^{+}=0.667 \text {, }
$$$$
\text { Area }_{2 R}^{+}=0.791 \text {, }
$$$$
\text { Area }_{3 R}^{+}=0.716 \text {, }
$$$$
\text { Area }_{4 R}^{+}=0.889 \text {, }
$$$$
\text { Area }_{5 R}^{+}=0.865 \text {. }
$$ 
TABLE 5: Chen rank of total fuzzy slack time for each path.

\begin{tabular}{lccc}
\hline Path & $X I_{A_{i}^{*}}$ & $X D_{A_{i}^{*}}$ & $\operatorname{Score}\left(A_{i}^{*}\right)$ \\
\hline $1-2-4-7$ & 2.881 & 1.605 & 0.232 \\
$1-2-5-7$ & 2.647 & 1.732 & 0.170 \\
$1-5-7$ & 2.659 & 1.556 & 0.211 \\
$1-3-5-7$ & 2.499 & 1.854 & 0.120 \\
$1-3-6-7$ & 2.536 & 1.824 & 0.132 \\
\hline
\end{tabular}

TABLE 6: Total float of each activity in the fuzzy project network.

\begin{tabular}{lcc}
\hline Activity & Fuzzy activity time & Total float \\
\hline $1-2$ & $(2,3,4,5,5,6,7,7)$ & $(0,0,0,0,7,13,19,25)$ \\
$1-3$ & $(4,4,5,6,7,7,8,9)$ & $(0,0,0,0,3,9,16,21)$ \\
$1-5$ & $(3,4,4,5,6,6,7,8)$ & $(0,0,6,10,15,20,25,30)$ \\
$2-4$ & $(5,5,6,7,8,8,9,10)$ & $(0,0,0,4,8,14,21,28)$ \\
$2-5$ & $(6,7,7,8,9,10,11,12)$ & $(0,0,0,0,7,13,19,25)$ \\
$3-5$ & $(8,9,10,11,12,14,15,16)$ & $(0,0,0,0,3,9,16,21)$ \\
$3-6$ & $(6,7,8,9,10,11,12,13)$ & $(0,0,0,0,4,10,17,22)$ \\
$4-7$ & $(10,12,14,15,15,16,18,20)$ & $(0,0,0,4,8,14,21,28)$ \\
$5-7$ & $(12,12,14,15,16,17,18,20)$ & $(0,0,0,0,3,9,16,21)$ \\
$6-7$ & $(13,13,15,16,17,18,19,20)$ & $(0,0,0,0,4,10,17,22)$ \\
\hline
\end{tabular}

TABLE 7: Total fuzzy slack time for each path in fuzzy project network.

\begin{tabular}{lcc}
\hline Path & $\begin{array}{c}\text { Total float } \\
(a, b, c, d, e, f, g, h)\end{array}$ & $\begin{array}{c}\text { Total fuzzy slack time } \\
(a+h, b, c, d, e, f, g, d+e)\end{array}$ \\
\hline $1-2-4-7$ & $(0,0,0,8,23,41,61,81)$ & $(81,0,0,8,23,41,61,31)$ \\
$1-2-5-7$ & $(0,0,0,0,17,35,54,71)$ & $(71,0,0,0,17,35,54,17)$ \\
$1-5-7$ & $(0,0,6,10,18,29,41,51)$ & $(51,0,6,10,18,29,41,28)$ \\
$1-3-5-7$ & $(0,0,0,0,9,27,48,63)$ & $(63,0,0,0,9,27,48,9)$ \\
$1-3-6-7$ & $(0,0,0,0,11,29,50,65)$ & $(65,0,0,0,11,29,50,11)$ \\
\hline
\end{tabular}

By using Area $_{i L}^{-}$, Area $_{i R}^{-}$, Area ${ }_{i L}^{+}$, Area $_{i R}^{+}$, and $\sigma_{A_{i}^{*}}$ from this we can get the values of $X I_{A_{i}^{*}}, X D_{A_{i}^{*}}$, and $\operatorname{Score}\left(A_{i}^{*}\right)$ values. The values are calculated and tabulated in Table 5.

Here, the path having minimum rank score is 1-3-5-7. So the required path for the fuzzy project network is 1-3-5-7.

6.3. Proposed Ranking Method for Octagonal Fuzzy Numbers. We considered Figure 2, the fuzzy activity times are represented by octagonal fuzzy numbers and fuzzy project activity, and total float is given in Table 6.

The possible paths, total float, and total fuzzy slack times are calculated and specified in Table 7.

By using (4)-(9), we can get the following values of Area $_{i L}^{-}$, Area $_{i R}^{-}$, Area $_{i L}^{+}$, Area $_{i R}^{+}$, and $\sigma_{A_{i}^{*}}$ :

$$
\begin{aligned}
& A_{1}^{*}=(1,0,0,0.098,0.283,0.506,0.753,0.382), \\
& \overline{a_{1}}=0.377, \\
& A_{2}^{*}=(0.876,0,0,0,0.209,0.432,0.666,0.209), \\
& \overline{a_{2}}=0.299,
\end{aligned}
$$

$$
\begin{aligned}
& A_{3}^{*} \\
& =(0.629,0,0.074,0.123,0.222,0.358,0.506,0.345), \\
& \overline{a_{3}}=0.282 \text {, } \\
& A_{4}^{*}=(0.777,0,0,0,0.111,0.333,0.592,0.111), \\
& \overline{a_{4}}=0.240 \text {, } \\
& A_{5}^{*}=(0.802,0,0,0,0.135,0.358,0.617,0.135), \\
& \overline{a_{5}}=0.255 \text {, } \\
& \sigma_{A_{1}^{*}}=0.361 \text {, } \\
& \sigma_{A_{2}^{*}}=0.330 \\
& \sigma_{A_{3}^{*}}=0.214 \\
& \sigma_{A_{4}^{*}}=0.296 \\
& \sigma_{A_{5}^{*}}=0.301 \text {, } \\
& \text { Area }_{1 L}^{-}=1.274 \text {, } \\
& \text { Area }_{2 L}^{-}=1.219 \text {, } \\
& \text { Area }_{3 L}^{-}=1.206 \text {, } \\
& \text { Area }_{4 L}^{-}=0.682 \text {, } \\
& \text { Area }_{5 L}^{-}=0.686 \text {, } \\
& \text { Area }_{1 R}^{-}=1.481 \text {, } \\
& \text { Area }_{2 R}^{-}=1.379 \text {, } \\
& \text { Area }_{3 R}^{-}=1.357 \text {, } \\
& \text { Area }_{4 R}^{-}=1.286 \text {, } \\
& \text { Area }_{5 R}^{-}=1.311 \text {, } \\
& \text { Area }_{1 L}^{+}=0.725 \text {, } \\
& \text { Area }_{2 L}^{+}=0.781 \text {, } \\
& \text { Area }_{3 L}^{+}=0.793 \text {, } \\
& \text { Area }_{4 L}^{+}=0.805 \text {, } \\
& \text { Area }_{5 L}^{+}=0.799 \text {, } \\
& \text { Area }_{1 R}^{+}=0.519 \text {, } \\
& \text { Area }_{2 R}^{+}=0.621 \text {, } \\
& \text { Area }_{3 R}^{+}=0.642 \text {, } \\
& \text { Area }_{4 R}^{+}=0.713 \text {, } \\
& \text { Area }_{5 R}^{+}=0.688 \text {. }
\end{aligned}
$$


TABLE 8: Chen rank of total fuzzy slack time for each path.

\begin{tabular}{lccc}
\hline Path & $X I_{A_{i}^{*}}$ & $X D_{A_{i}^{*}}$ & Score $\left(A_{i}^{*}\right)$ \\
\hline $1-2-4-7$ & 2.755 & 1.605 & 0.214 \\
$1-2-5-7$ & 2.598 & 1.732 & 0.162 \\
$1-5-7$ & 2.563 & 1.649 & 0.175 \\
$1-3-5-7$ & 2.968 & 1.814 & 0.032 \\
$1-3-6-7$ & 1.997 & 1.788 & 0.043 \\
\hline
\end{tabular}

TABLE 9: Comparison between three fuzzy numbers.

\begin{tabular}{lccc}
\hline Path & Triangular & Trapezoidal & $\begin{array}{c}\text { Proposed method } \\
\text { (octagonal) }\end{array}$ \\
\hline $1-2-4-7$ & 0.244 & 0.232 & 0.214 \\
$1-2-5-7$ & 0.208 & 0.170 & 0.162 \\
$1-5-7$ & 0.222 & 0.211 & 0.175 \\
$1-3-5-7$ & 0.186 & 0.120 & 0.032 \\
$1-3-6-7$ & 0.191 & 0.132 & 0.043 \\
\hline
\end{tabular}

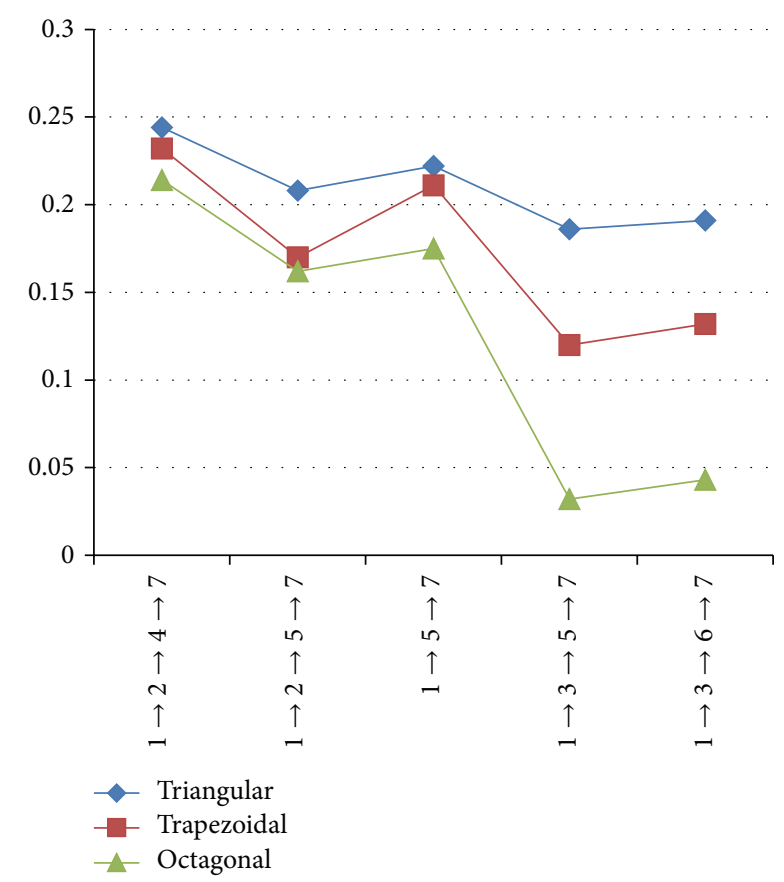

FIGURE 3: Comparison between proposed ranking method and existing ranking methods.

From Table 8, the path having minimum rank score is 1-35-7. So the critical path for the fuzzy project network is 1-3-5-7.

\section{Results and Discussion}

To verify the solution is to make an exhaustive comparison. From the above example, the Sanguansat and Chen ranking methods are applied for triangular and trapezoidal fuzzy numbers and our proposed modified ranking method using octagonal fuzzy number is also applied to identifying the fuzzy critical path. The results obtained through 3 procedures are tabulated (Table 9). From the table we are getting minimum score value in proposed ranking method. The proposed ranking method is better to find the critical path in a fuzzy project network. All these are represented in Figure 3 which plays a vital role in exhibiting the proposed ranking method by the simplest means that can be even understood by a layman.

\section{Conclusion}

Critical path method (CPM) has been a widely used method for complicated project in real life applications. This paper develops a simple modified ranking approach introduced to identify the fuzzy critical path. The modified arithmetic operations give that there is no negative time in fuzzy backward calculations. Octagonal fuzzy numbers were used to represent the activity duration in a project network. The results shows that octagonal fuzzy number is better to find the critical path in a fuzzy project network. Compared with other studies, the proposed approach can obtain more reasonable solution suitable for critical path activities.

\section{Competing Interests}

The authors declare that there are no competing interests regarding the publication of this paper.

\section{References}

[1] F. S. Hillier and G. J. Lieberman, Introduction to Operations Research, McGraw-Hill, New York, NY, USA, 7th edition, 2001.

[2] H. N. Ahuja, S. P. Dozzi, and S. M. Abourizk, Project Management, John Wiley \& Sons, New York, NY, USA, 1994.

[3] D. L. Mon, C. H. Cheng, and H. C. Lu, "Application of fuzzy distributions on project management," Fuzzy Sets and Systems, vol. 73, no. 2, pp. 227-234, 1995.

[4] D. Dubois, H. Fargier, and V. Galvagnon, "On latest starting times and floats in activity networks with ill-known durations," European Journal of Operational Research, vol. 147, no. 2, pp. 266-280, 2003.

[5] A. M. Natarajan, P. Balasubramani, and A. Tamilarasi, Dorling Kindersley, 2006.

[6] R. Sivarenthinamohan, Operations Research, Tata McGraw-Hill Publishing, 2005.

[7] W. S. Khalaf, "Solving the fuzzy project scheduling problem based on a ranking function," Australian Journal of Basic and Applied Sciences, vol. 7, no. 8, pp. 806-811, 2013.

[8] M. H. Oladeinde and D. O. Itsisor, "Application of Fuzzy theory to project scheduling with critical path method," Journal of Applied Sciences and Environmental Management, vol. 17, no. 1, pp. 161-166, 2013.

[9] N. Shahsavari Poura, M. Kheranmandb, M. Fallahc, and S. Zeynalid, "A new method for critical path method with fuzzy processing time," Management Science Letters, vol. 1, pp. 347-354, 2011.

[10] R. Soundararajan, A. Ramesh, S. Sivasankaran, and A. Sathishkumar, "Modeling and analysis of mechanical properties of aluminium alloy (A413) processed through squeeze casting route using artificial neural network model and statistical technique," Advances in Materials Science and Engineering, vol. 2015, Article ID 714762, 16 pages, 2015. 
[11] L. A. Zadeh, "Fuzzy sets as a basis for a theory of possibility," Fuzzy Sets and Systems, vol. 1, no. 1, pp. 3-28, 1978.

[12] G.-S. Liang and T.-C. Han, "Fuzzy critical path for project network," Information and Management Sciences, vol. 15, no. 4, pp. 29-40, 2004.

[13] R. Jain, "A procedure for multi-aspect decision making using fuzzy sets," International Journal of Systems Science, vol. 8, no. 1, pp. 1-7, 1977.

[14] S. Chanas and S. Radosinski, "A model of activity performance time in the light of fuzzy sets theory," Problemy Organizacji, vol. 2, pp. 68-76, 1976.

[15] M. H. Oladeinde and C. A. Oladeinde, "An investigation into the decision makers's risk attitude index ranking technique for fuzzy critical path analysis," Nigerian Journal of Technology, vol. 33, no. 3, pp. 345-350, 2014.

[16] T.-C. Han, C.-C. Chung, and G.-S. Liang, "Application of fuzzy critical path method to airport's cargo ground operation systems," Journal of Marine Science and Technology, vol. 14, no. 3, pp. 139-146, 2006.

[17] F.-T. Lin, "Critical path method in activity networks with fuzzy activities duration times," in Proceedings of the IEEE International Conference on Systems, Man and Cybernetics, vol. 2, pp. 1155-1160, IEEE, October 2001.

[18] N. Ravi Shankar, V. Sireesha, and P. Phani Bushan Rao, "Critical path analysis in the fuzzy project network," Advances in Fuzzy Mathematics, vol. 5, no. 3, pp. 285-294, 2010.

[19] M. Karimirad, F. Jolai, and M. Zowghi, "Ordering of fuzzy quantities based on upper and lower bounds," World of Sciences Journal, pp. 83-91, 2013.

[20] E. Rotarescu, "Applying pert and critical path method in human resource training," Review of General Management, vol. 14, no. 2, pp. 187-201, 2011.

[21] S. Kazemi, S. M. Homayouni, and J. Jahangiri, "A fuzzy delphianalytical hierarchy process approach for ranking of effective material selection criteria," Advances in Materials Science and Engineering, vol. 2015, Article ID 845346, 12 pages, 2015.

[22] S. Narayanamoorthy and S. Maheswari, "Fuzzy critical path method (FCPM) based on Sanguansat and Chen Ranking method and Centroid method," International Journal of Mathematical Archive, vol. 3, no. 11, pp. 4737-4743, 2012. 

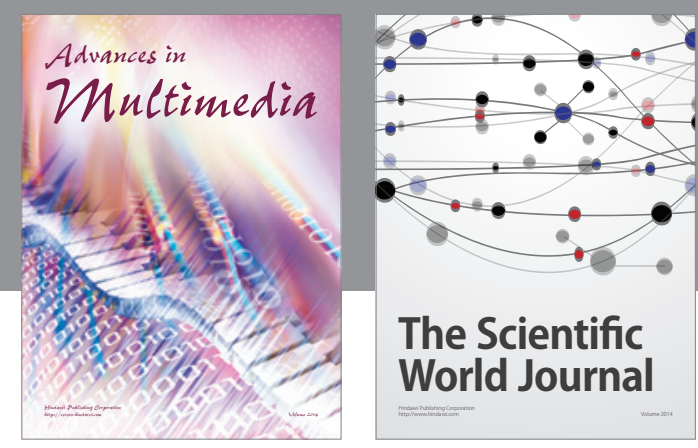

The Scientific World Journal
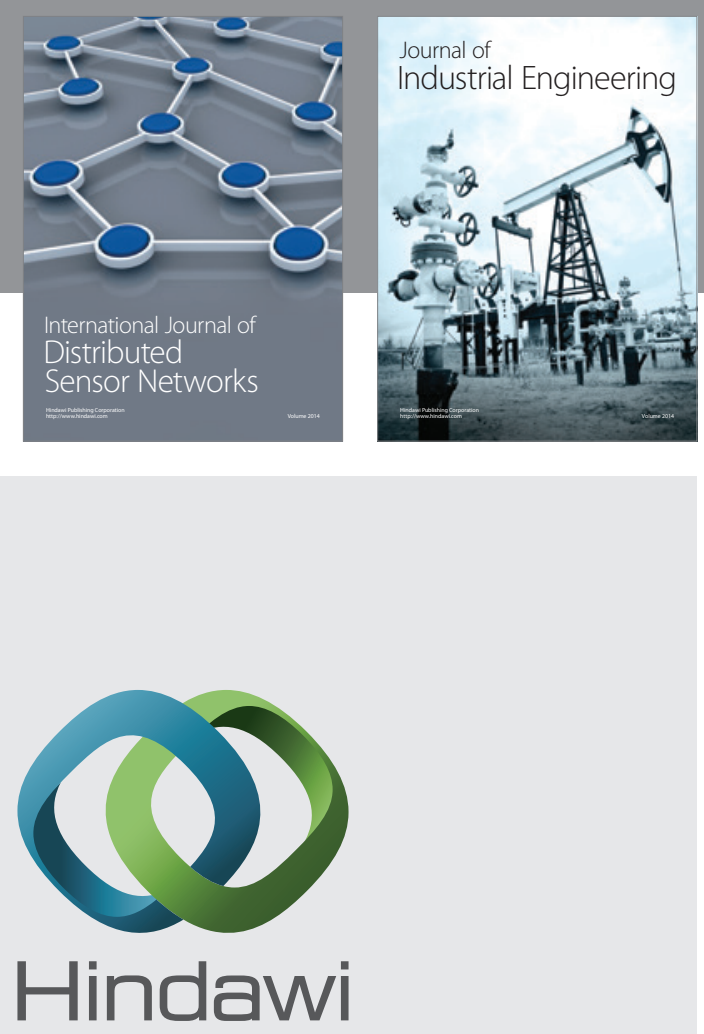

Submit your manuscripts at

http://www.hindawi.com

\section{Computer Networks} and Communications
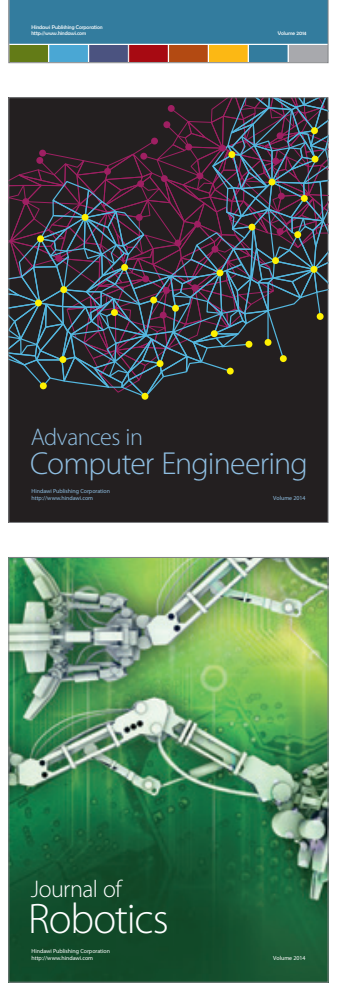
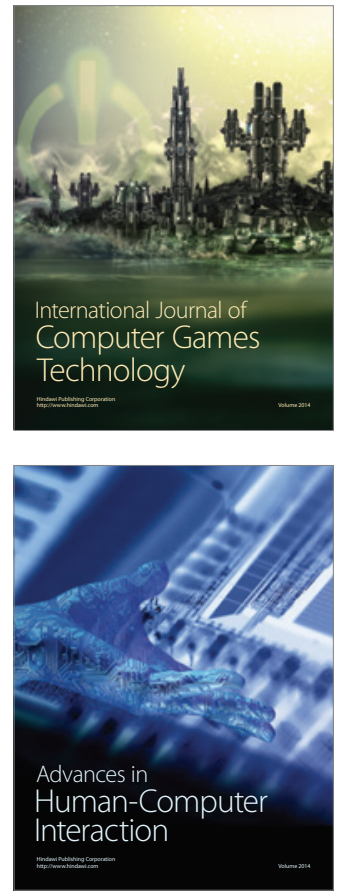
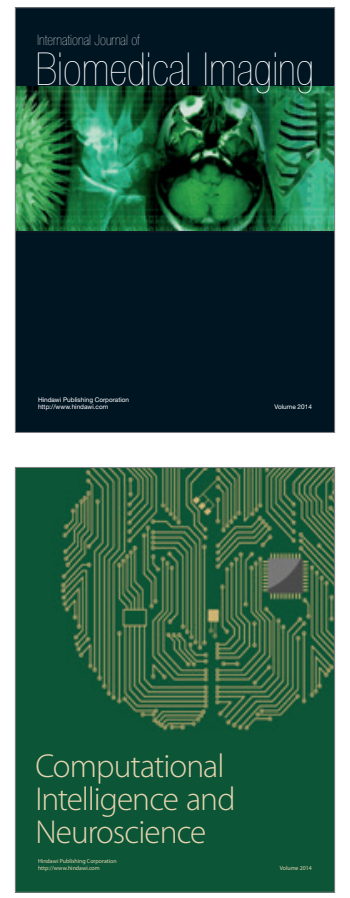
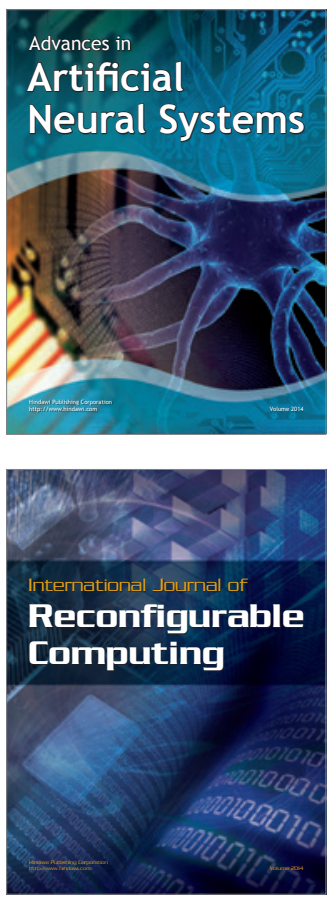
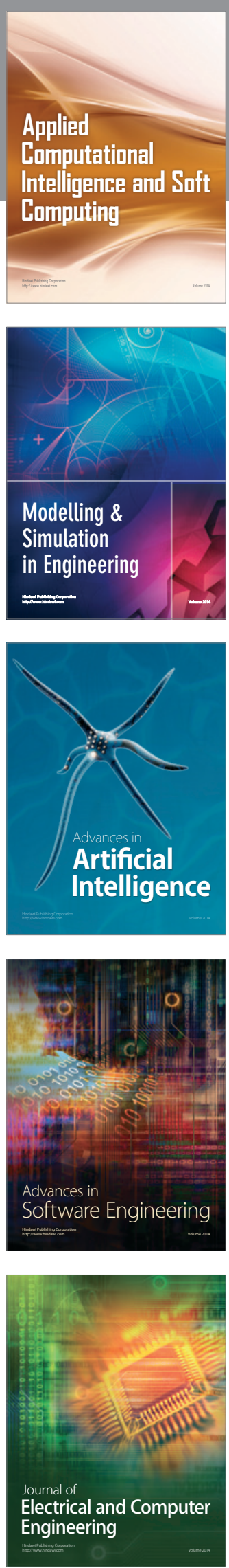